\title{
A Review of the Psychological Aspects of COVID-19
}

\author{
Shivani Bitra \\ Medical Intern,Jawaharlal Nehru Medical College,Datta Meghe Institute \\ of Medical Sciences,Sawangi, Wardha, Maharashtra, India. \\ Corresponding author email: shivbitra@gmail.com
}

\section{ABSTRACT}

COVID-19 has proved to be a factor to cause excessive anxiety among people. The group affected includes a wide population from people who were living in their homes with their families, who were living alone, people working from home, also includes healthcare workers, patients and their relatives. The lack of information about anxiety disorders and the way to deal with it would cause a long-term effect on the people across the world.Lockdown, quarantines, social distancing, wearing mask became the 'New Normal'. The fear of virus made us more sick mentally. Based on evolution, we are social animals. Desire for socialization is the primary motivator for us to constantly connect with each other. While running within chaos and spending hours for work, socializing has been a vent. It helps us relax and ease our pain. A sudden stoppage to be able to talk it out has let all the stress to accumulate. So while working on prevention of the spread of Covid-19, measures need to be taken to reduce depression, anxiety and stress among the general population.This article tries to reflect on the psychological trauma which Covid-19 inflicted throughout the world.

KEY WORDS: PSYCHOLOGICAL, MENTAL EFFECTS, DEPRESSION, SOCIAL DISTANCING, TRAUMA, COVID19.

\section{INTRODUCTION}

Anxiety is a normal emotion. It's your brain's way of reacting to stress and alerting you of potential danger ahead. Everyone feels anxious now and then. For example, you may worry when faced with a problem at work, before taking a test, or before making an important decision. But anxiety disorders are different. According to the American Psychiatric Association, anxiety disorders are the most common type of psychiatric disorders (American Psychiatric Association). They're a group of mental illnesses that cause constant and overwhelming anxiety and fear. The excessive anxiety can make you avoid work, school, family get-togethers, and other social situations that might trigger or worsen your symptoms.

Biosc Biotech Res Comm P-ISSN: 0974-6455 E-ISSN: 2321-4007

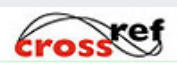

Identifiers and Pagination

Year: 2021 Vol: 14 No (6) Special Issue

Pages: 197-201

This is an open access article under Creative

DOI: $h t t p: / / d x$.doi.org/10.21786/bbrc/14.6.42
Commons License Attribn 4.0 Intl (CC-BY).
These disorders include separation anxiety disorder, selective mutism, specific phobia, social anxiety disorder (social phobia), panic disorder, agoraphobia, generalized anxiety disorder, substance/medication-induced anxiety disorder, and anxiety disorder due to another medical condition (American Psychiatric Association). COVID19 has proved to be a factor to cause excessive anxiety among people. The group affected includes a wide population from people who were living in their homes with their families, who were living alone, people working from home, also includes healthcare workers, patients and their relatives. The lack of information about anxiety disorders and the way to deal with it would cause a longterm effect on the people across the world.

The Care Givers: Don S. Dizon, MD, during the initial days of pandemic wrote, "I'm awaiting orders, like a soldier at war. But I can't see the enemy. I see the havoc that it has wrought upon the world, in China, Italy, Spain, and New York City. I'm standing witness to a world on lockdown, where a hug may turn into a cluster of contagion. Multiple times a day I hear these words repeated-a different mantra, one for hospital staff: Prepare for the surge. Will tomorrow bring the same level of anxiety? Will all hell break loose?" (Medscape, 2020) significant proportion

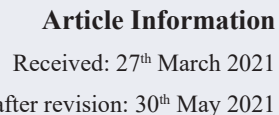

ccepted after revision: $30^{\text {th }}$ May 2021 
of healthcare workers treating patients exposed to COVID-19 have symptoms of depression, anxiety, and insomnia.Frontline COVID-19 healthcare workers across North America are dealing with unprecedented stress, but mental health therapists in both Canada and the US are doing their part to ensure the psychological well-being of their colleagues on the frontlines of the pandemic.

Over the past few weeks, thousands of licensed psychologists, psychotherapists, and social workers have signed up to offer free therapy sessions to healthcare professionals who find themselves psychologically overwhelmed by the pandemic's economic, social, and financial fallout (Medscape, 2020).The researchers conducted a cross-sectional survey of 1257 healthcare workers in 34 hospitals across China, including the outbreak epicenter Wuhan.Among survey respondents, $61 \%$ were nurses, 39\% were physicians, $61 \%$ worked in hospitals in Wuhan and 42\% were frontline healthcare workers working in the department involving diagnosis, care of COVID-19 positive patients and their treatment. Half of respondents reported symptoms of depression, $45 \%$ reported symptoms of anxiety, 34\% reported symptoms of insomnia, and about $72 \%$ reported psychological distress (Medscape, 2020).

Pregnancy in Pandemic: According to a study conducted in Canada, women pregnant during the pandemic are twice as likely as their pre-COVID-19 counterparts to meet the criteria for major depressive or anxiety disorders. The researchers found that pregnant womenthroughout this period were more likely to experience negativity and symptoms of severe depression and anxiety with greater changes in insight and mood before the pandemic, even after they controlled for gestational age, income, history of psychiatric diagnoses, and education. And clinically significant levels of anxiety and depression were more common in the COVID-era pregnancy group than in the pre-COVID group (10.9\% vs 6.0\%). Berthelot pointed to data showing that anxiety, depression, and traumatic events duringpregnancy are the strongest predictors of postpartum depression (Medscape, 2020).

Dailywage Workers, Migration and Anxiety: The lower social economic group has been dealing with its own sets of problems, being unemployed with savings not enough to feed a family of three or four. Daily wage workers and the sudden cessation of work and travel. Living in an overcrowded space. Making decisions to stuff themselves in claustrophobic containers just to reach their native place or walking miles leading to dehydration and death. The news channels in India were flooded with evidences of such instance. On the off chance that anything positive has emerged from the Covid-19 emergency, it is that the world's most severe lockdown uncovered the situation of the weak Indian traveler workforce. With no work and no real way to take care of themselves, eliminated from family support, millions had no real option except to oppose the lockdown and get back to their towns.

In a steady progression, they walked, conveying their things and kids, strolling a huge number of kilometers, resolved to discover a way home, catching the creative mind of the world (Medscape, 2020). COVID-19 has a mental effect, as the laborers are stressed over the families back home. That is the motivation behind why many are reluctant to remain back regardless of whether enterprises return. They desire to return once regularity returns," (Medscape, 2020).This not just endangered the wellbeing of these laborers and presented them to the danger of Coronavirus contamination yet additionally pushed their nervousness levels on the pinnacle.

The Locked In Humans: A public study from the American Psychiatric Association (APA) shows COVID19 is genuinely influencing Americans' emotional wellbeing, with half of US grown-ups revealing undeniable degrees of nervousness. The study information were gotten from a broadly delegate test of 1004 grown-ups from March 18-19. Respondents were generally white (74\%) and went in age from 18 to 91 years (mean age, $\sim 47$ years). Practically 50\% of review respondents $(48 \%)$ revealed they had a sensation of nervousness and stress of getting influenced by COVID-19 and 40\% of respondents dreaded the demise because of obscure. They had a dread of getting seriously sick. The greater part (62\%) of these are living in the dread of their life partners, youngsters and guardians succumbing to this infection. $36 \%$ of respondents said this sudden cessation of their life and work is affecting their mental state and most (59\%) said it's having a serious impact on their day to day activities.

Surviving in the tough times, pandemic has resulted in monetary issues and thus fear of shortage of food, supplies and medicines for them and their family. Therefore, 57\% said this pandemic has caused a great impact on their finances and 68\% are concerned about the post Covid impact on the economy (Medscape, 2020). "The increased stress and uncertainty may trigger their symptoms or make them worse than they were before," said Jeff Szymanski, executive director of the International OCD Foundation in Boston. "The rapid development of COVID-19 has all the elements of the four U's - unfamiliar, unpredictable, uncontrollable, uncertain - the perfect recipe for anxiety and OCD," Wagner told Reuters Health (Medscape, 2020). Internet search results data analysis shows, increased searches for 'anxiety' after the pandemic started. Cumulatively, all acute anxiety searches were $11 \%$ higher than expected for the 58-day study period $(95 \% \mathrm{CI}, 7 \%-14 \%)$. There was a dramatic increase in searches $(375,000)$, or a total of 3.4 million searches, during that period (Medscape, 2020).

The Smart-Addictions: With an available cell phone in each hand there is expanded reliance via online media and our telephone screens have bolted our psyches during this pandemic. Something that was made to assist us with advancing human have now made us the captives of specialized developments. The calculations keep us stuck to the telephone with each revive button. Looking over has removed the force of our psyches to think past our abilities. At the point when an individual uses his/her wireless more often than not, incapable to scale back PDA 
utilization, utilizing cells as an answer for fatigue, feeling uneasiness or wretchedness when your telephone is out of your reach, losing your connections. Examination says "when phone use turns into an enslavement, the conduct gets distressing".

Salvatore Insiga, a neurosurgeon at Northwell Health's Neuroscience Institute in Manhasset, New York, thought about that regardless that there is no strong evidence between wireless radiation and tumor hazard yet the chance actually exists. Youths are at high danger of being cell phone addicts (Cha S-S et.al., 2018). Reliance on devices and cynicism in the personalities straightforwardly influence one another. It builds the danger of creating gloom and tension in close future (Rosen LD, et. al. 2013). Obviously, individuals' emotional well-being was seriously influenced during pandemics like SARS. For instance, Leung et al. in their investigation found that his respondents announced encountering tension during SARS (Leung G,et. al. 2003).

Moreover, stress, despondency, and uneasiness were likewise discovered to be normal among individuals during SARS. Nonetheless, these were essentially higher for the high-hazard populace, for example, wellbeing workers (McAlonan GM, et. al. 2007). (Hawryluck et al.2004) discovered that individuals who were isolated during SARS revealed an undeniable degree of mental distress. Plainly, being social is a human inclination that works with social communication, and subsequently, when our developments are abridged, mental pain results (Jones R, et.al. 2020). (Van Bortel et al. 2016 and Kumar and Nayar, 2020) have proposed that issues of emotional well-being ought to be thought of and furthermore tended to as tension, stress, dread, injury, defenselessness and other mental issues are capable during a pandemic.

Children and Adolescents: The current state has also has its impact on mental health of children and adolescents. The main concerns aredeveloping anxiety, reduced contacts among peers and unbalanced stress regulation. Children living in homes with domestic violence and maltreatment of children and mentally ill parents are also a matter of great concern. Getting out used to be an escape for children with troubled home.A child with special needs, disabilities,mental health problems, migrant background or low socioeconomic status and trauma experiences may have trouble living under these restricted conditions. With all the ongoing challenges, children safety and mental health have been a matter of concern. Its an urgent need to reach out to these children to limit the long term consequences (Fegert JM,et.al. 2019). Such various instances prove that mental health education is equally important in this pandemic.

\section{MATERIAL AND METHODS}

Study Design: Observational Study

RESULTS
Frontline healthcare workers had a higher risk of depressive symptoms (OR, 1.52; 95\% CI, $1.11-2.09$; P $=.01)$, anxiety $(0 \mathrm{R}, 1.57 ; 95 \% \mathrm{CI}, 1.22-2.02 ; \mathrm{P}<.001)$, insomnia (OR, 2.97; 95\% CI, $1.92-4.60 ; \mathrm{P}<.001)$, and distress (OR, 1.60; 95\% CI, $1.25-2.04 ; \mathrm{P}<.001$ )

\section{DISCUSSION}

A pandemic was the last thing any of us would have thought about. It's a sudden pause that changed our perspective towards life. The fear of virus has made us more sick mentally.Based on evolution, we are social animals. Want for socialization is hard wired into our qualities and our minds far more grounded than any craving to have out-of-home fun or amusement. It is the essential helper of why we continually associate with one another. While running within chaos and spending hours for work, socializing has been a vent. It helps us relax and ease our pain. A sudden stoppage to be able to talk it out has let all the stress to accumulate. The difference between 'Empathy and Sympathy' was the first thing we are taught as medical students.

Infact, we are taught about empathy before anatomy. And I think that's where we need to start again. Breathing in PPE's might be difficult butcare givers including doctors, nurses and workers in the hospital are working day and nights in their shifts despite the challenges. The fear will remain in the back our minds no matter who you are. And that's where the role of our peers, colleagues, even patients come up. Having an exchange of understanding would start a change that is much needed. The role of a psychiatrist is crucial. Taking help from our fellow doctors is the start of the actual treatment if needed.

\section{World Health Organization (WHO):}

- have systematically explained a complete guide to stay healthy at home. Some of the key points include:

- Knowledge and insight to know the difference between right and wrong information. Keep yourself informed about the latest updates by trusted organizations.

- Have a fixed routine. Having a schedule will keep you calm and organized. Physical exercise have profound positive impacts on anxiety and depression. It helps you sleep better and also releases endorphins which trigger the positive feeling.

- There is a lot of information out there. Minimize newsfeeds that makes you feel anxious or distressed.

- Keep in regular contact with people close to you by telephone and internet. Talking to them will help you ease.

- A rush of nicotine or alcohol is never the answer to your anxiety, boredom or social isolation. Limit the alcohol intake and avoid as much as possible.

- Smartly restrict your screen time. Make sure that you take regular breaks from on-screen activities. It is tempting more than it is relaxing. Keep a right balance between offline activities and screen time.

- Social media can be misleading with a lot of fake 
news and stories. It's important to know the right source of information. If you are able to, offer support to people in your community who may need it, such as helping them with food shopping. Especially the old and dependent part of community by keeping your safety first.

- While you have an option to stay home and restrict your activities by working from home, there are a whole group of people who walk out of their homes everyday just to do their job by helping others. Be thankful to these people.

- Fear is a normal. Confusion and uncertainty is normal. But letting it hurt others is not. Kindness is always an option. Don't discriminate people who are covid positive. Don't discriminate their families. If you can, help each other while keeping the distance and safety. Remember, we are all in this together as a humans. Stop discriminating on any grounds.

- This applies to all the sections of the population. The need to spread awareness is key to a healthy mind in current conditions.

The problem with workers and lower socio economic groups was seen to be solved with governmental bodies and some people aiding them with transportation, food and shelters. While this getting solved, we forgot the scars this experiences must have carved on their minds. Unable to understand the signs their mind gives, these people should not love with it. The only way is to make them aware about it. Only with knowledge comes the understanding. And with it comes the courage to ask for help when needed. Making these people aware about the importance of mental health at the grassroot level should be incorporated. Physicians can help patients focus on the "4 C's" to cope during this time: remain calm, create consistency, find containment for their compulsions, and care for themselves and others.

"There are two main take-home messages from our research - one is that we need to think about how to address acute anxiety during COVID-19, and the other is that we need to startthinking about how our messaging impacts acute anxiety," said Ayers, who is also vice chief of innovation, Division of Infectious Diseases and Global Public Health, UCSD. In Covid-19 pandemic, emphasis is given in primary prevention, to limit the spread of infection. So basic precautions like hand hygiene (Mathur, P. 2011), restricted public contact, limited movement and travel (Toshida, T., and Chaple J 2020, Ather B, et. Al. 2020, Shah, P., and Naqvi W 2020) can help a lot to prevent the spread of Covid-19. Also measures need to be taken to reduce depression, anxiety and stress among the general population (Gaidhane $S, 2020)$. Few of the related studies on Covid-19 were reported (Jachak, S., P. et. al. 2020, Joseph, M.B., et. al. 2020, Joshi, K., N. et.al. 2020, Khatib, M.N., et. al. 2020 and Lakhkar, B.B., et. al. 2020).

Various aspects of mental health issues were reflected in studies of (Spoorthy et. al. 2020 , Groveret. Al, 2015, Shahidet. al. 2019, Behereet. Al 2020, Gawai et.al. 2020). While we treat the virus symptomatically, we should also treat the setbacks COVID-19 is causing in the minds of people. These group of people could be anyone from the ones reading it to the ones around us. The ones who know about mental health issues but don't know where to seek help to the ones who don't know what they are feeling. Maybe there will be more patients of anxiety disorders than people affected by Corona Virus by the end of it, well whenever it will be. While we are conducting trials for vaccines, we should be prepared for the amount of help these people will be needing.

Conflicts of Interest: There is no conflict of interest.

\section{Ethical Approval: From IEC, DMIMS Wardha}

Funding: DMIMS, Wardha

\section{REFRENCES}

American Psychiatric Association. URL: https://www. psychiatry.org/patients-families/anxiety-disorders. American Psychiatric Association. Diagnostic and Statistical Manual of Mental Disorders. 5th ed. Arlington, VA: APA Press; 2013

Ather, B., Mirza, T.M. and Edemekong, P.F., 2020. Airborne precautions. StatPearls [Internet].

Behere, P.B., Nagdive, A.B., Behere, A.P., Yadav, R. and Fernandes, R., 2020. Innovation in Community Psychiatry for the Delivery of Mental Health Services: The Sawangi Model. Journal of Neurosciences in Rural Practice, 11(4), p.593.

Cha, S.S. and Seo, B.K., 2018. Smartphone use and smartphone addiction in middle school students in Korea: Prevalence, social networking service, and game use. Health psychology open, 5(1), p.2055102918755046. COVID-19 Diary Day 5: Facing Deployment - Medscape - Apr 09, 2020

COVID-19: Higher Depression, Anxiety Risk for Pregnant Women - Medscape - Jun 11, 2020.

COVID-19: Mental Health Pros Come to the Aid of Frontline Comrades - Medscape - Apr 02, 2020.

COVID-19: 'Record' Spike in Internet Anxiety, Panic Queries - Medscape - Aug 26, 2020.

COVID-19: 'Striking' Rates of Anxiety, Depression in Healthcare Workers - Medscape - Mar 26, 2020.

Doctors Should Reach Out to OCD Patients During COVID-19, Experts Say - Medscape - Apr 03, 2020.

Fegert, J.M., Vitiello, B., Plener, P.L. and Clemens, V., 2020. Challenges and burden of the Coronavirus 2019 (COVID-19) pandemic for child and adolescent mental health: a narrative review to highlight clinical and research needs in the acute phase and the long return to normality. Child and adolescent psychiatry and mental health, 14, pp.1-11.

For migrant workers, anxiety abounds about return to home towns and future jobs. The Hindu- May 3,2020 Jones, R., Woods, C. and Usher, K., 2020. The impact of media sensationalism and crisis framing on stigma and negative attitudes towards methamphetamine users. 
Gaidhane, S., Khatib, N., Zahiruddin, Q.S., Gaidhane, A., Telrandhe, S. and Godhiwal, P., 2020. Depression, anxiety and stress among the general population in the time of COVID-19 lockdown: A cross-sectional study protocol. International Journal of Research in Pharmaceutical Sciences, 11(Special Issue 1).

Galea, S., Merchant, R.M. and Lurie, N., 2020. The mental health consequences of COVID-19 and physical distancing: the need for prevention and early intervention. JAMA internal medicine, 180(6), pp.817818.

Gawai, J.P., Singh, S., Taksande, V.D., Sebastian, T., Kasturkar, P. and Ankar, R.S., 2020. Critical Review on Impact of COVID 19 and Mental Health.

Grover, S., Avasthi, A., Shah, S., Lakdawala, B., Chakraborty, K., Nebhinani, N., Kallivayalil, R.A., Dalal, P.K., Sinha, V., Khairkar, P. and Mukerjee, D.G., 2015. Indian Psychiatric Society multicentric study on assessment of health-care needs of patients with severe mental illnesses. Indian journal of psychiatry, 57(1), p.43.

Hawryluck, L., Gold, W.L., Robinson, S., Pogorski, S., Galea, S. and Styra, R., 2004. SARS control and psychological effects of quarantine, Toronto, Canada. Emerging infectious diseases, 10(7), p.1206.

High Anxiety in America Over COVID-19 - Medscape - Mar 28, 2020.

Jachak, S., Phansopkar, P. and Naqvi, M.W., 2020. Impact of covid-19 in India, a disastrous pandemic outbreak. International Journal of Research in Pharmaceutical Sciences, 11(Special Issue 1).

Joseph, M.B., Pohekar, S., Raut, A. and Patil, M., 2020. The palliative care and covid-19 pandemic. International Journal of Research in Pharmaceutical Sciences, 11(Special Issue 1).

Joshi, K., Acharya, N., Acharya, S. and Joshi, S., 2020. A grave situation with COVID in the gravid: A narrative review. International Journal of Research in Pharmaceutical Sciences, pp.496-499.

Khatib, M.N., Gaidhane, S., Khatib, M., Ahmed, M., Gaidhane, A. and Syed, Z.Q., 2020. SARS-CoV and SARS-CoV-2: Similar viruses with different trajectories. Wutan Huatan Jisuan Jishu, 16(5).

Lakhkar, B.B., Guru, B., Damke, S. and Damke, S., Most Susceptible Duo in COVID-19 Crisis: A Literature Review. Perinatology, 21, pp.112-23.

Latchoumi, T.P., Ezhilarasi, T.P. and Balamurugan, K.,
2019. Bio-inspired weighed quantum particle swarm optimization and smooth support vector machine ensembles for identification of abnormalities in medical data. SN Applied Sciences, 1(10), pp.1-10.

Leung, G.M., Lam, T.H., Ho, L.M., Ho, S.Y., Chan, B.H.Y., Wong, I.O.L. and Hedley, A.J., 2003. The impact of community psychological responses on outbreak control for severe acute respiratory syndrome in Hong Kong. Journal of Epidemiology \& Community Health, 57(11), pp.857-863.

Mathur, P., 2011. Hand hygiene: back to the basics of infection control. The Indian journal of medical research, 134(5), p.611.

McAlonan, G.M., Lee, A.M., Cheung, V., Cheung, C., Tsang, K.W., Sham, P.C., Chua, S.E. and Wong, J.G., 2007. Immediate and sustained psychological impact of an emerging infectious disease outbreak on health care workers. The Canadian Journal of Psychiatry, 52(4), pp.241-247.

Rosen, L.D., Whaling, K., Carrier, L.M., Cheever, N.A. and Rokkum, J., 2013. The media and technology usage and attitudes scale: An empirical investigation. Computers in human behavior, 29(6), pp.2501-2511.

Shaheed, R., Shukla, S., Acharya, S., Gopal, U. and Acharya, N., 2019. Journey from Fighters to Survivors: Quality of Life and Mental Status in Cancer Patients in a Rural Tertiary Care Hospital. Journal of Clinical \& Diagnostic Research, 13(8).

Shah, P. and Naqvi, W., 2020. Fighting and chasing the rogue virus-covid 19. International Journal of Research in Pharmaceutical Sciences, 11(Special Issue 1).

Spoorthy, M.S., Pratapa, S.K. and Mahant, S., 2020. Mental health problems faced by healthcare workers due to the COVID-19 pandemic-A review. Asian journal of psychiatry, 51, p.102119.

The five truth about the migrant workers crisis | opinionHindustan Times.

Toshida, T. and Chaple, J., 2020. „Covid-19-Rumours and Facts in Media区. International Journal of Research in Pharmaceutical Sciences, 11(1).

Van Bortel, T., Basnayake, A., Wurie, F., Jambai, M., Koroma, A.S., Muana, A.T., Hann, K., Eaton, J., Martin, S. and Nellums, L.B., 2016. Psychosocial effects of an Ebola outbreak at individual, community and international levels. Bulletin of the World Health Organization, 94(3), p.210. 